\title{
Supporting Early-Career Academics in the UK Computer Science Community
}

\author{
Tom Crick ${ }^{*}$ \\ Swansea University \\ Swansea, UK \\ thomas.crick@swansea.ac.uk
}

\author{
James H. Davenport ${ }^{*}$ \\ University of Bath \\ Bath, UK \\ j.h.davenport@bath.ac.uk
}

\author{
Alan Hayes* \\ University of Bath \\ Bath, UK \\ ah347@bath.ac.uk
}

\author{
Alastair Irons* \\ Sunderland University \\ Sunderland, UK \\ alastair.irons@sunderland.ac.uk
}

\author{
Tom Prickett ${ }^{*}$ \\ Northumbria University \\ Newcastle upon Tyne, UK \\ tom.prickett@northumbria.ac.uk
}

\section{CCS CONCEPTS}

\begin{abstract}
The early career of a computer science academic in the United Kingdom (UK) - as with most other disciplines - is challenging in terms of balancing research aspirations, learning and teaching responsibilities, wider academic service commitments, as well as their own professional development. In terms of learning and teaching development, this commonly involves working towards Fellowship of the Higher Education Academy (now known as Advance $\mathrm{HE}$ ), either by direct application or via successful completion of an accredited institutional taught postgraduate course. Typically, if a course is required (often as part of their academic probation), the focus will be general higher education learning and teaching pedagogy rather than specifically focused on computer science and cognate areas. The formal institutional course requirements are normally supplemented by mentoring from within their department from experienced academic colleagues. Thus, the quality of development for an early-career academic will be enhanced in part by the strength of the community of practice operating within the department and the communities of practice that exist at a national and international level, often through professional bodies, learned societies and sub-disciplinary groupings. This paper presents the work-in-progress to address some of these structural, cultural and community challenges at both the institutional and national level in the UK, based on empirical themes collected from a workshop held at UKICER'20. We identify a number of specific actions and recommendations to supplement the current formal institutional requirements with enhanced national-level academic practice support and professional development, alongside local and regional professional mentoring.
\end{abstract}

\footnotetext{
${ }^{*} N . B$. all authors contributed equally to this paper
}

Permission to make digital or hard copies of all or part of this work for personal or classroom use is granted without fee provided that copies are not made or distributed for profit or commercial advantage and that copies bear this notice and the full citation on the first page. Copyrights for components of this work owned by others than ACM must be honored. Abstracting with credit is permitted. To copy otherwise, or republish, to post on servers or to redistribute to lists, requires prior specific permission and/or a fee. Request permissions from permissions@acm.org.

CEP '21, fanuary 7, 2021, Durham, United Kingdom

(C) 2021 Association for Computing Machinery.

ACM ISBN 978-1-4503-8959-4/21/01 ..\$15.00

https://doi.org/10.1145/3437914.3437977
- Social and professional topics $\rightarrow$ Professional topics.

\section{KEYWORDS}

Early-career academics, community of practice, professional development, computer science education

\section{ACM Reference Format:}

Tom Crick, James H. Davenport, Alan Hayes, Alastair Irons, and Tom Prickett. 2021. Supporting Early-Career Academics in the UK Computer Science Community. In Computing Education Practice 2021 (CEP '21), January 7, 2021, Durham, United Kingdom. ACM, New York, NY, USA, 4 pages. https://doi.org/10.1145/3437914.3437977

\section{WHAT IS IT?}

This paper outlines the work-in-progress to address the structural, cultural and community challenges at both the institutional and national level in the UK. It reports progress from a project exploring, developing and delivering an initiative to supplement institutionbased professional development and training available to earlycareer computer science academics, with an offering of regional and national activities. It describes the work undertaken to date to research, co-design and develop a training course for those new to teaching computer science in the UK.

This initiative began via sector-led discussions regarding how the computer science education community could be better supported at BCS Academy of Computing Board and the Institute of Coding. This was followed by the recruitment of a steering group of computer science academics, from across a representative range of UK universities. The academic career profile and experience of the academics involved is deliberately diverse; it includes junior academics to more senior academics, as well as a number of members of the professoriate and senior members of BCS Academy of Computing. The views of this steering committee were combined with the outcomes of a workshop at the ACM UK \& Ireland Computing Education Research Conference 2020 (UKICER'20), to formulate a pilot training course. The training course will be first run in December 2020, so initial findings and progress can be shared at this conference. This paper presents an overview of the co-design of the trial run of the training programme, as well as the key outcomes from the workshop which took place in September 2020. 


\section{WHY ARE YOU DOING IT?}

There are a number of disciplinary challenges which are well documented within computer science education, including substantial changes in national curricula and qualifications [4]. Attrition and failure rates can be high, with students learning programming for perhaps the first time remaining a significant challenge [7, 14, 20]; new priority areas such as cybersecurity [5]; as well as a range of issues impacting failure rates [17, 24]. Student satisfaction as measured by major national surveys is reported as commonly below that of other disciplines [21]; concerns related to the employment prospects of graduates have been reported as inferior to other disciplines, especially across STEM [19]. Effectively addressing these disciplinary challenges involves a number of evolving pedagogic approaches, as well as wider system and societal issues. To become a confident and capable computer science academic (from a learning $\&$ teaching perspective) requires maintaining currency in terms of specialist subject knowledge (and how their own research informs their practice), but also fluency in how to respond to the education challenges the discipline presents.

The complex demands of UK higher education make the early career of an academic challenging [22] and potentially lonely [9], especially when balanced against their research aspirations (or indeed, institutional benchmarks), and wider professional service commitments. Professional development in the UK commonly involves working towards Fellowship of the Higher Education Academy (FHEA) ${ }^{1}$, either by direct application to Advance HE or by an accredited university postgraduate course. Typically, this is supported by mentoring from within a department. The quality of learning provided will be promoted in part by the strength of the community of practice operating within the department [13] and the communities of practice that exist at a national and international level [22].

Simultaneously mastering the challenges of "learning the craft" and those of how to become an effective and successful academic can be fraught. However, some mechanisms already exist to better support this professional development. For a number of years, mentoring has been recognised as a important mechanism in the development of academics, with formal mentoring now common as part of the process of on-boarding early-career academics. Commonly this takes the form of an experienced academic providing support for an early-career colleague. Mentoring has been highlighted as part of a set of activities help diversify the staff base [11]. While such mechanisms can be very effective, limiting guidance and support to one source rather than a wider and more diverse community can be limiting [8]. Informal mentoring can also be very effective, but it is not without issue. For example, it has been reported that women can feel marginalised from informal mentoring partnerships [10]. In the UK, Black, Asian and Minority Ethnic (BAME) colleagues are "poorly represented in both senior academic and university leadership roles: of 19,000 people employed as professors in the United Kingdom, only 400 are BAME women. In a typical gathering of 100 professors, 90 would be white and there would be just two BAME women." [23, p. I]. There are a plethora of issues that continue to reinforce aspects of this of this inequality [1]. Policy recommendations have been made (including new models for mentoring and the establishing of support networks [2]), and initiatives developed and executed

\footnotetext{
${ }^{1}$ https://www.advance-he.ac.uk/fellowship
}

(including Athena Swan ${ }^{2}$ and the Race Equality Charter ${ }^{3}$. Equally, research suggests that care needs to be taken not to conflate issues of race and gender [3], or some of the challenges being faced may not be addressed. Research related to cross-gender or cross-racial mentoring is relatively rare, however it has been reported that cross-racial mentoring between faculty and students can work if an ally development model is employed [18]. Clearly, ally work can be challenging and will require continual reflection, perseverance and careful consideration of power and positions in response to repression [16]. However the distance and absence of direct power structures between universities may make it more straightforward to function as an ally in a cross-university mentoring relationship which is unburdened by managerial or organisational concerns. Such mentoring relationships are also likely to be educational for the mentors, who would also be promoting and giving back to the community. Ideally, the mentoring will evolve into a longer term relationship which are mutually beneficial and help to promote and facilitate work-based learning for the academics involved.

\section{WHERE DOES IT FIT?}

In the UK, early-career academics will have had varied prior experience; including: postdocs taking up their first academic appointment at the start of their academic career; postdocs who are teaching as part of their career development in preparation for applying for a permanent academic position; $\mathrm{PhD}$ students, aspiring to an academic career, with significant teaching responsibilities; established international academics new to the UK HE sector; junior academics who have been in a temporary post for a few years; those moving from FE into their first HE job; those moving from industry into their first HE job; and CS academics at institutions who do not currently specify that their lecturing staff complete a PG teaching qualification.

In any given year, the number of individuals across these profiles will vary; but with over one hundred higher education institutions in the UK that teach computing at undergraduate or postgraduate level, there is usually at least one faculty member in this position, hence there exists a potentially large group of individuals who could benefit from this proposed professional development programme.

For the pilot phase of this programme (which will run in December 2020), a training course will be run for invited early-career academics based at the institutions of the members of the steering committee. The programme includes live online sessions presented by colleagues from UK computer science departments. For interested attendees, the intention is to supplement the programme with the provision of cross-institution mentoring.

\section{DOES IT WORK?}

The workshop at UKICER'20, focused upon addressing three research questions:

i) What current and future opportunities are there to engage new faculty with a UK CS Education Community of Practice? ii) What is the potential to supplement institutional development opportunities with national development opportunities?

\footnotetext{
${ }^{2}$ https://www.advance-he.ac.uk/equality-charters/athena-swan-charter

${ }^{3}$ https://www.advance-he.ac.uk/charters/race-equality-charter
} 
iii) How can we continue to raise the profile and value of new research faculty members engaging with computer science education research?

Engagement in computer science education research is not the same as engaging in computer science education practice; however it can be a reasonable proxy for understanding the wider domain challenges. At the UKICER'20 workshop, the attendees engaged in a facilitated session to encourage discussion of key issues, providing responses to a set of questions using an online collaborative environment. The input from the 21 attendees generated a number of insights into the challenges faced by early-career computer science academics. After the workshop, the online interactions and responses were analysed using open coding analysis in order to identify key themes:

Inconsistent institutional support. Variable institutional-level support was identified. Some colleagues reported little support for new faculty with respect to learning and teaching; others reported postgraduate training programmes or even higher apprenticeships. Competing priorities and resource constraints. Balancing alternative pressures (especially research) came out strongly as a key challenge in increasing interest in computer science education. Hence any training course has to be designed with direct benefit for attendees.

Changing negative perceptions. A few participants commented less favourable regarding how computer science education was seen in their home universities, together with a wish to support initiatives the raised its profile and perceived value.

Islands of excellence. There are a number of intuitions within the UK with significant (or developing) research interests in computer science education (for example: Glasgow, KCL, Kent, Napier); the majority of others institutions lacked such support or structures. It was suggested that in some cases further collaboration with Education departments may also be of benefit. Elsewhere, some colleagues reported the absence of computer science education research groups and the related infrastructure to promote the importance of computer science education.

Local and other initiatives. A number of local initiatives exist, together with a growing number of national initiatives (as discussed in the following section); this suggests there is an appetite for disciplinary-specific professional development initiatives such as this one.

A developing UK community. The national computer science education community was seen as a very positive development and further initiatives that intended to strengthen or grow the community appeared to be well received.

\section{WHO ELSE HAS DONE THIS?}

It is reported that the most commonly employed mechanism for continuing professional development (CPD) is conversations between peers [12]. A number of communities exist to support these conversations at the local, national and international level. Internationally this development is supported by the groupings such as ACM Special Interest Group in Computer Science Education (SIGCSE) or the IEEE Education Society. These international professional bodies run a number of conferences to promote discussion and dialog as well as dissemination of ideas. The UK \& Ireland SIGCSE Chapter further promotes the community-building by running annual Computing Education Practice (CEP) and Computing Education Research (UKICER) conferences. However, whilst early-career academics are welcome to attend, the conferences and seminars are not directly aimed a the needs of early-career academics who may in any case find it challenging to obtain funding for attendance. The ACM UK SIGCSE Chapter also holds Twitter meets and runs a computer science education research journal club. Whilst earlycareer computer science academics are very much welcome to join in these discussions, they are not the primary target market. Some universities have centres which further promote these conversations, such as the Centre for Computing Science Education at the University of Glasgow ${ }^{4}$. And as identified in both the 2012 and 2017 Royal Society reviews of computing education in the UK, there is a small (but growing) base in UK universities. In summary, the international and national Initiatives help promote a community that experienced academics can access to provide CPD; however the CPD for early-career academics is less developed, particularly for those at institutions who do not have established centres or CSE research groups.

In addition to training programmes run by individual Universities, in the UK, Advance HE runs training programmes for academics at different stages of their career, alongside their legacy "subject centres". However this training is not discipline-specific. The UK's Council of Professors and Heads of Computing (CPHC) run occasional workshops in a variety of issues. The most pertinent offering for new faculty has been the "Chair in 10 Years" workshop which is aimed at facilitating medium-to-long-term academic career planning. Whilst this is a well received contribution, it does not directly support the development needs of new faculty with respect to high-quality learning, teaching and assessment.

As well as generic pedagogic challenges, most disciplines including computer science have a range of discipline specific challenges. The Institute of Mathematics and its Applications (IMA) for a number of years has ran a training course intended to welcome new faculty to the community and help address key discipline-related pedagogic challenges [15].

\section{WHAT WILL YOU DO NEXT?}

The recent mapping and analysis highlights that there is space within the UK computer science community of practice to establish a new training programme for early-career computer science academics that augments what is already provided by individual institutions. However discussions within the steering group of academics highlight a few questions that would benefit from being answered in order to appropriately design the new programme including:

Motivation to attend. Early-career colleagues have limited time, so the course needs to be directly beneficial to their learning \& teaching practice.

Building a community. The course needs to facilitate the growing of the community between the attendees and links to the wider

\footnotetext{
${ }^{4}$ https://www.gla.ac.uk/research/az/ccse/
} 
community of practice in the UK.

Professional alignment. Preliminary discussions have taken place with Advanced HE and BCS, The Chartered Institute for IT; both are supportive of the initiative in principle. Discussions are ongoing regarding how it aligns to professional recognition.

Delivery mode. At the time of writing the only possible mode is online; other modes may be more suitable in the longer term.

Prototype course. All these questions require the input of earlycareer colleagues to resolve. These questions will be explore at the trial course in December 2020. This course will provide: guidance upon issues the steering group believes are critical; a panel which will seek to address three questions from each attendees; and a workshop to explore the development needs of early-career computer science academics.

\section{WHY ARE YOU TELLING US THIS?}

The UK's computer science education community of practice has evolved and developed rapidly in recent years, which presents the opportunity to review and celebrate the current achievements. As part of this review, this project has identified a significant opportunity to establish: (i) a national training programme for those new to teaching computer science in the UK, which will augment institutional professional development and training opportunities; and (ii) a national mentoring programme for those new to teaching computer science in the UK, supplemented by local and regional networks. These parallel initiatives are intended to adopt the ally model which is facilitated by the cross-institutional nature of the initiative. In doing so, as well as supporting the continued focus on high-quality learning, teaching and assessment in computer science (with a specific focus on effective pedagogic approaches), and the further development of the UK's computer science education community of practice, it is intended to provide attendees an ally who can help them address sector and system-level racial and gender inequalities that persist in UK higher education (as well as the wider IT profession).

The initiative presents a range of opportunities for those at various points of their academic career. For those at an early career stage, the initiative presents a further source of valuable professional development and extension of their professional networks outside of their institution. For those with more experience, as the initiative develops so will opportunities to become involved and support activities both within their institution, as well as across the sector. If the approach is effective, and the community wishes to see it extended then the involvement of experienced colleagues in its development, delivery and enhancement as mentors will be critical to ensure wide access and engagement. Finally, opting for a blended learning approach also takes into consideration the longer-term impacts of the COVID-19 pandemic on the UK higher education sector, especially considering its specific impact on the computer science education community [6].

\section{REFERENCES}

[1] Jason Arday. 2020. Fighting the tide: Understanding the difficulties facing Black, Asian and Minority Ethnic (BAME) Doctoral Students' pursuing a career in Academia. Educational Philosophy and Theory 0, 0 (2020), 1-8. https://doi.org/10. $1080 / 00131857.2020 .1777640$

[2] Kalwant Bhopal. 2014. The experiences of BME academics in higher education: aspirations in the face of inequality. Leadership Foundation for Higher Education
Stimulus Papers (2014).

[3] Kalwant Bhopal and Holly Henderson. 2019. Competing inequalities: gender versus race in higher education institutions in the UK. Educational Review 0, 0 (2019), 1-17. https://doi.org/10.1080/00131911.2019.1642305

[4] Neil C. C. Brown, Sue Sentance, Tom Crick, and Simon Humphreys. 2014. Restart: The Resurgence of Computer Science in UK Schools. ACM Transactions on Computer Science Education 14, 2 (2014), 1-22. https://doi.org/10.1145/2602484

[5] Tom Crick, James H. Davenport, Paul Hanna, Alastair Irons, and Tom Prickett. 2020. Overcoming the Challenges of Teaching Cybersecurity in UK Computer Science Degree Programmes. In Proc. 50th Annual Frontiers in Education Conference (FIE 2020). IEEE Press.

[6] Tom Crick, Cathryn Knight, Richard Watermeyer, and Janet Goodall. 2020. The Impact of COVID-19 and "Emergency Remote Teaching" on the UK Computer Science Education Community. In Proc. UK \& Ireland Computing Education Research (UKICER) Conference. https://doi.org/10.1145/3416465.3416472

[7] James H. Davenport, Alan Hayes, Rachid Hourizi, and Tom Crick. 2016. Innovative Pedagogical Practices in the Craft of Computing. In Proc. 4th International Conference on Learning and Teaching in Computing and Engineering (LaTiCE 2016). 115-119. https://doi.org/10.1109/LaTiCE.2016.38

[8] Suzanne C. De Janasz, Sherry E. Sullivan, and Vicki Whiting. 2003. Mentor networks and career success: Lessons for turbulent times. Academy of Management Perspectives 17, 4 (2003), 78-91.

[9] Kenneth E. Foote and Michael N. Solem. 2009. Toward better mentoring for early career faculty: results of a study of US geographers. International fournal for Academic Development 14, 1 (2009), 47-58. https://doi.org/10.1080/ 13601440802659403

[10] Sharon K Gibson. 2006. Mentoring of women faculty: The role of organizational politics and culture. Innovative Higher Education 31, 1 (2006), 63-79.

[11] Leana Golubchik and Mallory Redel. 2018. Diversity in Faculty Recruiting: A WiSE Approach. SIGMETRICS Perform. Eval. Rev. 46, 1 (June 2018), 140-142. https://doi.org/10.1145/3292040.3219676

[12] Helen King. 2004. Continuing Professional Development in Higher Education: what do academics do? Planet 13, 1 (2004), 26-29. https://doi.org/10.11120/plan. 2004.00130026

[13] Klara Bolander Laksov, Sarah Mann, and Lars Owe Dahlgren. 2008. Developing a community of practice around teaching: a case study. Higher Education Research \& Development 27, 2 (2008), 121-132. https://doi.org/10.1080/07294360701805259

[14] Ellen Murphy, Tom Crick, and James H. Davenport. 2017. An Analysis of Introductory Programming Courses at UK Universities. The Art, Science, and Engineering of Programming 1(2), 18 (2017), 23. https://doi.org/10.22152/programmingjournal.org/2017/1/18

[15] Institute of Mathematics and its Applications. 2019. Induction Course for New Lecturers in the Mathematical Sciences 2019. https://ima.org.uk/11361/inductioncourse-for-new-lecturers-in-the-mathematical-sciences-2019/

[16] Lori D. Patton and Stephanie Bondi. 2015. Nice white men or social justice allies?: using critical race theory to examine how white male faculty and administrators engage in ally work. Race Ethnicity and Education 18, 4 (2015), 488-514. https: //doi.org/10.1080/13613324.2014.1000289

[17] Tom Prickett, Morgan Harvey, Julie Walters, Longzhi Yang, and Tom Crick. 2020. Resilience and Effective Learning in First-Year Undergraduate Computer Science. In Proc. 25th Annual Conference on Innovation and Technology in Computer Science Education. https://doi.org/10.1145/3341525.3387372

[18] Richard J. Reddick and Katie Ortego Pritchett. 2016. " I Don't Want to Work in a World of Whiteness:" White Faculty and Their Mentoring Relationships with Black Students. Fournal of the Professoriate 8, 1 (2016).

[19] Nigel Shadbolt. 2016. Review of computer sciences degree accreditation and graduate employability. https://www.gov.uk/government/publications/computerscience-degree-accreditation-and-graduate-employability-shadbolt-review.

[20] Simon, Raina Mason, Tom Crick, James H. Davenport, and Ellen Murphy. 2018. Language Choice in Introductory Programming Courses at Australasian and UK Universities. In Proc. 49th ACM Technical Symposium on Computer Science Education. 852-857. https://doi.org/10.1145/3159450.3159547

[21] Jane Sinclair, Matthew Butler, Michael Morgan, and Sara Kalvala. 2015. Measures of Student Engagement in Computer Science. In Proc. 2015 ACM Conference on Innovation and Technology in Computer Science Education. 242-247. https: //doi.org/10.1145/2729094.2742586

[22] J. Denard Thomas, Laura Gail Lunsford, and Helena A. Rodrigues. 2015. Early career academic staff support: evaluating mentoring networks. Fournal of Higher Education Policy and Management 37, 3 (2015), 320-329. https://doi.org/10.1080/ 1360080X.2015.1034426

[23] Universities UK. 2019. Black, Asian and Minority Ethnic Student Attainment at UK Universities. https://www.universitiesuk.ac.uk/policy-andanalysis/reports/Documents/2019/bame-student-attainment-uk-universitiesclosing-the-gap.pdf

[24] Christopher Watson and Frederick W. B. Li. 2014. Failure Rates in Introductory Programming Revisited. In Proc. 2014 Conference on Innovation \& Technology in Computer Science Education. 39-44. https://doi.org/10.1145/2591708.2591749 